\title{
Conhecimento Didático do Professor de Matemática à Luz de um Processo Formativo
}

\section{Didactic Knowledge of the Mathematics Teacher in Light of a Formative Process}

\author{
Eurivalda Santana* \\ ORCID iD 0000-0001-6156-1205 \\ João Pedro da Ponte** \\ ORCID iD 0000-0001-6203-7616 \\ Maria de Lurdes Serrazina*** \\ ORCID iD 0000-0003-3781-8108
}

\begin{abstract}
Resumo
Este estudo tem como objetivo principal analisar as perspectivas e os conhecimentos evidenciados nos relatos de uma professora que atuava em salas de aula do $3^{\circ}$ ano do Ensino Fundamental, antes e depois de um processo formativo em que ela participou. Utilizamos a análise descritiva e interpretativa de um questionário do perfil da professora, de um questionário de avaliação final da formação e de uma entrevista semiestruturada realizada dois anos depois do fim do processo formativo. Para analisar os dados, aportamo-nos às ideias a respeito do conhecimento didático do professor de Matemática. Os resultados indicam que, antes do processo formativo, a professora revela dificuldades com o respectivo conhecimento, bem como sobre seu ensino e suas perspectivas negativas. Depois da realização do processo formativo, suas perspectivas passam a ser positivas, assumindo novas posturas a respeito do conhecimento da Matemática, do aluno, seus processos de aprendizagem e sobre o conhecimento dos processos de trabalho na sala de aula de Matemática.
\end{abstract}

Palavras-chave: Formação. Conhecimento didático. Conhecimento profissional.

\begin{abstract}
\footnotetext{
* Doutora em Educação Matemática pela Pontifícia Universidade Católica de São Paulo (PUC/SP). Líder do Grupo de Pesquisa em Educação Matemática, Estatística e em Ciências (GPEMEC). Professora do Departamento de Ciências Exatas e Tecnológicas da Universidade Estadual de Santa Cruz (UESC), Ilhéus, Bahia, Brasil. Endereço para correspondência: Rua Pernambuco, 153, Apto. 102, Jardim Vitória, CEP 45605 510, Itabuna, Bahia, Brasil. E-mail: eurivalda@uesc.br.

** Doutor em Educação Matemática pela Universidade da Georgia (UGA), EUA. Professor catedrático do Instituto de Educação da Universidade de Lisboa (IE, ULisboa), Lisboa, Portugal. Endereço para correspondência: Instituto de Educação, Alameda da Universidade, 1649-013 Lisboa, Portugal. E-mail: jpponte@ie.ulisboa.pt.

"Doutora em Educação Matemática pela Universidade de Londres (UK). Professora coordenadora aposentada da Escola Superior de Educação do Instituto Politécnico de Lisboa, Portugal. Membro integrado da Unidade de Investigação em Desenvolvimento e Formação do Instituto de Educação da Universidade de Lisboa, Portugal. Endereço para correspondência: Rua Luís de Queirós, 26 - $9^{\circ} \mathrm{E}, 2800-698$ Almada, Portugal. E-mail: lurdess@eselx.ipl.pt.
} 
This study aims to analyze the perspectives and knowledge evidenced in the reports of a Third grade elementary school teacher, before and after a formative process in which she participated. We use descriptive and interpretative analysis of a teacher profile questionnaire, a final evaluation questionnaire, and a semi structured interview conducted two years after the end of the formative process. We analyzed the data based in the ideas about the didactics knowledge of the mathematics teacher. The results indicate that, before the formative process, the teacher displayed difficulties with mathematics knowledge and its teaching and held negative perspectives about mathematics. After completing the formative process, her perspectives were more positive and she took up new positions regarding mathematics knowledge, the students, and their learning processes and the knowledge of the work processes in the mathematics classroom.

Keywords: Education. Didactics knowledge. Professional knowledge.

\section{Introdução}

Na literatura, é possível identificar pesquisas como as de Ponte e Oliveira (2002), Ferreira (2003), Lopes (2003), Santana, Alves e Nunes (2015) e Oliveira e Passos (2017) que abordam a formação de professores e têm buscado compreender a relação entre a formação de professores, suas ações nas atividades de sala de aula e a formação continuada, no sentido de promover o seu desenvolvimento profissional. Procura-se saber de que modo os processos formativos podem estimular e envolver o professor no desenvolvimento de sua autonomia em sala de aula e em seu papel para a aprendizagem do estudante.

No que diz respeito à Matemática, assumimos, tal como Ponte (2012), que o ensino de qualidade da mesma perpassa por pontos, tais como: a formação matemática adequada para os professores; o desenvolvimento das competências no campo da didática da Matemática; as condições que o professor precisa ter para tomar decisões favoráveis e estabelecer o contexto do ensino e da aprendizagem. Para contemplarmos esse "ensino de Matemática de qualidade" é preciso investir na formação adequada dos professores, o que justifica os esforços que vêm sendo canalizados nas pesquisas para compreender e estabelecer processos formativos e modelos de prática formativa que dialoguem com o professor, sua prática na sala de aula e favoreçam a sua mobilização de conhecimentos. Pesquisas como as de Elbaz (1983), Ponte e Oliveira (2002), Jaworski (2003, 2006) e Ball, Mark e Geoffrey (2008) discutem a respeito das possibilidades de mobilização de conhecimentos feita por professores em processos formativos e apontam a sua importância para o desenvolvimento das ações profissionais e da prática letiva dos professores que ensinam Matemática.

Motivados pela possibilidade de desenvolver um processo formativo que dialogasse com o professor, com o seu fazer em sala de aula e a mobilização de conhecimentos aportamo-nos a um modelo de prática formativa desenvolvido por Magina et al. (2018) denominado espiral RePARe e que, tal como o modelo de Korthagen (2001), procura 
interligar prática e teoria. Ele parte das noções de desenvolvimento profissional do professor, de prática reflexiva de Schön (2000) e busca definir as fases para um processo formativo que possibilite a reflexão a partir de um processo dialético de reflexão-planejamento-açãoreflexão, tendo sido usado nas pesquisas de Santana (2013) e Santana, Alves e Nunes (2015). Nesse contexto, desenvolvemos um processo formativo durante um ano escolar e temos, para o presente estudo, a seguinte questão de pesquisa: quais perspectivas e conhecimentos são evidenciados nos relatos de uma professora, antes e depois da sua participação num processo formativo baseado na espiral RePARe?

\section{Conhecimento profissional do professor}

A formação continuada de professores assume diferentes vertentes de pesquisa, entre as quais estão os estudos referentes aos conhecimentos mobilizados pelos professores no processo formativo. Shulman (1986) afirma a importância de o professor ter conhecimento do conteúdo, bem como o que designa por "conhecimento pedagógico do conteúdo". O autor elenca sete domínios de conhecimento de base: do conteúdo; pedagógico geral; do currículo; pedagógico do conteúdo; dos estudantes e das suas características; dos contextos educacionais e das metas; finalidades e valores da educação. Entre esses domínios, o conhecimento pedagógico do conteúdo é de interesse especial, considerando-se o papel central na atividade docente (SHULMAN, 1987).

No âmbito do ensino e da atuação do professor de Matemática, pesquisadores têm proposto outras noções para descrever o seu conhecimento profissional. Ball, Mark e Geoffrey (2008) referenciam o conhecimento pedagógico do conteúdo definido por Shulman (1986, 1987), mas focam no que os professores precisam saber sobre Matemática, como e onde os professores podem usar esse conhecimento na prática. Para os autores, o domínio do conhecimento matemático para o ensino pode ser subdividido em: conhecimento do conteúdo e conhecimento pedagógico do conteúdo. O primeiro, tendo o foco no objeto matemático, é concebido como conhecimento comum do conteúdo, conhecimento do horizonte do conteúdo e conhecimento especializado do conteúdo. Os autores consideram que o segundo, cujo foco está no ensino da Matemática, pode subdividir-se em conhecimento do conteúdo e dos estudantes, conhecimento do conteúdo e do ensino e conhecimento do conteúdo e do currículo.

Analisando as ações dos professores em sala de aula, Ponte e Oliveira (2002), Ponte e Chapman (2006) e Ponte (2012) apontam outras vertentes do conhecimento do professor. Para 
Ponte e Oliveira (2002), o conhecimento profissional do professor "refere-se a atividades socialmente reconhecidas, realizadas em domínios de prática bem definidos" (p. 3). Esse conhecimento refere-se à ação do professor em sala de aula no exercício de sua profissão e inclui, também, "a visão do professor sobre o seu próprio desenvolvimento profissional" (PONTE; OLIVEIRA, 2002, p. 4).

Compreender as aprendizagens, os conhecimentos mobilizados e o próprio desenvolvimento profissional do professor, impulsionados por um processo formativo, envolve que ele tenha uma visão sobre suas perspectivas que podem ser sustentadas em ações anteriores ou posteriores ao processo formativo. As perspectivas baseadas em ações anteriores dizem respeito a atitudes, reflexões e pensamentos fundamentados em experiências anteriores ao processo formativo. As perspectivas baseadas em ações posteriores dizem respeito a intenções futuras que podem ser expressas em forma de atitudes, reflexões e pensamentos que aportam no processo formativo e se projetam para o futuro. Esses dois tipos de perspectivas se referem à esfera do conhecimento profissional dimensionada para as relações inerentes ao contexto de ação desse profissional e seu fazer em sala de aula. As perspectivas emergentes do conhecimento profissional são elaboradas pelas experiências individuais e sociais próprias do exercício das ações da profissão do professor. Essas experiências vão desde a aprendizagem dos estudantes até as questões sociais que envolvem o contexto escolar, o próprio conteúdo da matéria a lecionar e a maneira de gerir a sala de aula. Essas experiências caracterizam o conhecimento prático do professor (ELBAZ, 1983).

No exercício das ações profissionais, o professor efetiva sua prática em sala de aula que interliga fatores que se influenciam mutuamente. Por exemplo, Jaworski e Potari (1998) utilizam uma tríade de ensino para analisar o papel do professor que define a prática de ensino em: (i) gestão da aprendizagem, que envolve as regras e normas para que seja possível o professor e o estudante atuarem de modo a ocorrer o processo de ensino e de aprendizagem; (ii) sensibilidade para conhecer o estudante e gerir as interações com ele e (iii) desafio matemático, no sentido de desafiar o estudante para se engajar nas tarefas propostas em sala de aula. Essa tríade delineia uma interligação entre fatores que descrevem a prática profissional do professor.

É possível associar diferentes vertentes do conhecimento profissional às ações peculiares do exercício prático da profissão do professor. Quando nos referimos nomeadamente ao professor de Matemática, temos especificidades peculiares para essa área. Ponte e Oliveira (2002) associam esse conhecimento à prática letiva, designam-no como conhecimento didático e diferenciam quatro vertentes: conhecimento da Matemática, 
conhecimento do currículo, conhecimento do aluno e de seus processos de aprendizagem e o conhecimento dos processos de trabalho na sala de aula.

O conhecimento da Matemática refere-se à interpretação que o professor faz a esse respeito para trabalhar em sala de aula. Circunscreve a visão que o professor tem sobre a Matemática e de como ensinar conceitos, relações, propriedades e teoremas, bem como identifica quais pontos considera importante para trabalhar em sala de aula. Não se refere exatamente ao saber científico posto pela ciência, mas à "adaptação" que o professor faz para colocar o saber científico na sua prática da sala de aula.

O conhecimento do currículo como vertente do conhecimento didático do professor de Matemática "diz respeito ao currículo e ao modo como o professor faz a gestão curricular" (PONTE, 2012, p. 88). Envolve o conhecimento das orientações curriculares estabelecidas em nível macro e micro dos sistemas educacionais aos quais está associado e a gestão do conteúdo matemático a ser trabalhado em sala de aula, bem como os mecanismos de ensino e de avaliação a serem utilizados. Refere-se a toda uma gestão do que ensinar, como ensinar e como avaliar o desenvolvimento do estudante em determinado conteúdo, podendo fazer ligações com os objetivos gerais postos pelo sistema de educação.

O conhecimento do aluno e de seus processos de aprendizagem envolve, além de conhecê-lo como estudante, percebê-lo como uma pessoa inserida num contexto social, levando em conta que cada um deles possui interesses e pontos de vista diferenciados. Deve ser considerada também a sua condição como aprendiz que é influenciada pelo contexto de vida em que se encontra. Com relação ao professor, o "seu conhecimento sobre estas questões [é] fundamental para o exercício do seu papel profissional” (PONTE, 2012, p. 88).

A quarta vertente do conhecimento didático do professor está relacionada com as ações a serem desenvolvidas em sala de aula no que diz respeito aos processos de ensino e de aprendizagem. Esses processos vão desde a forma de planejar as ações para um ano letivo, para um período letivo ou para uma aula específica, à tomada de decisões do que ensinar e como ensinar, até a forma de conduzir as aulas, de intervir com os estudantes e de desenvolver os processos avaliativos.

A visão do conhecimento profissional do professor de matemática na perspectiva de conhecimento didático possibilita analisar os conhecimentos mobilizados pelos professores em suas ações profissionais. Essas ações envolvem a prática do professor em sala de aula. 


\section{Modelo de prática formativa}

As práticas formativas para professores em serviço podem ser orientadas no sentido de promover o seu desenvolvimento profissional. Nesse sentido, buscamos implementar um processo formativo que possibilite o diálogo entre teoria e prática de sala de aula. Korthagen e Kessels (1999) e Korthagen (2001) apresentam um modelo de prática formativa que liga teoria e prática visando a mudança da pedagogia do professor em sala de aula. Elegem três princípios para que a aprendizagem seja mais efetiva durante o processo formativo: (i) direcionar para as necessidades do estudante; (ii) embasar-se nas experiências dos estudantes e (iii) refletir sobre suas próprias experiências. Nesse modelo, a discussão e as reflexões sobre a prática são efetivamente realizadas num elo entre pesquisadores e escola.

A espiral RePARe é um modelo de prática formativa de professor em serviço que apresenta similaridades com o Modelo de Korthagen e colaboradores. Essa espiral, concebida por Magina et al. (2018), foi estabelecida a partir da prática de pesquisa com formação de professores de Matemática, utilizando-se a perspectiva do trabalho colaborativo, no qual professores e escolas atuam em parceria com pesquisadores, estudantes de graduação e de pós-graduação (Figura 1). Em conformidade com a definição de Pinto e Leite (2014, p. 148), o trabalho colaborativo é um "trabalho em conjunto (dois ou mais sujeitos) com benefício para o desenvolvimento profissional dos envolvidos". Assumimos, nesta pesquisa, a espiral RePARe como modelo de prática formativa.

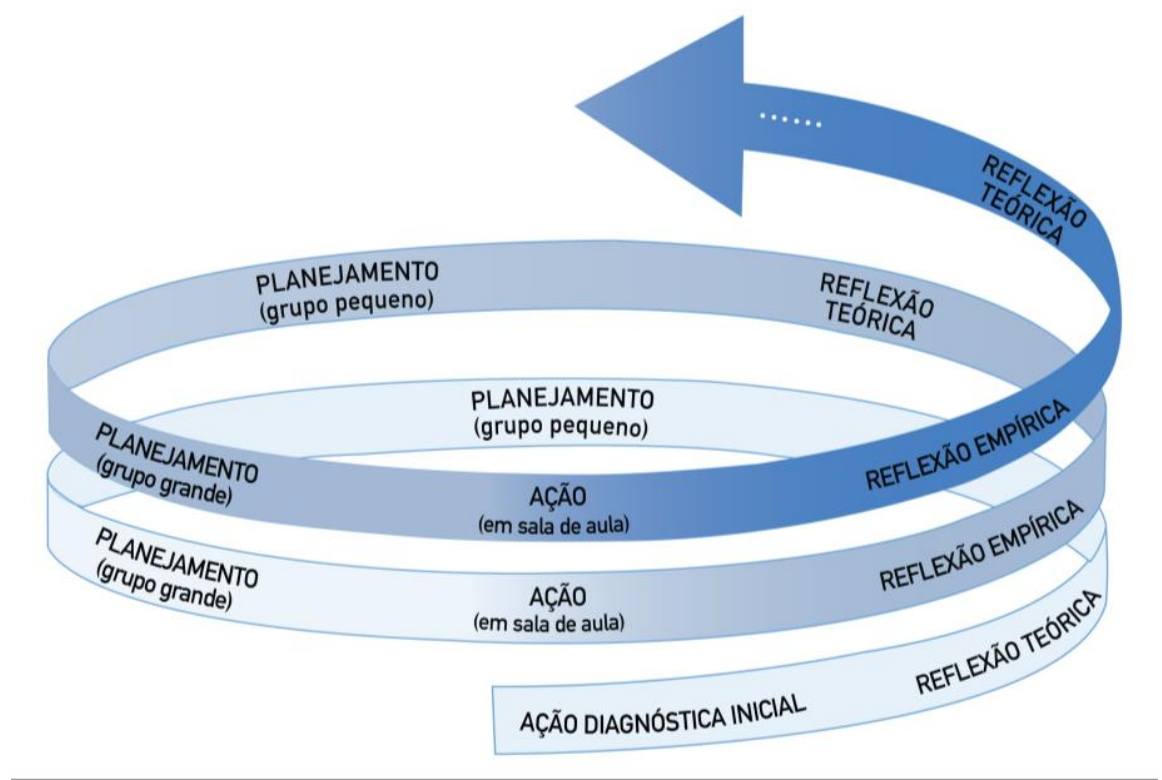

Figura 1 - Modelo da espiral RePARe

Fonte: Magina et al. (2018) 
A dinâmica desse modelo de formação em serviço toma como base um processo dialético de reflexão-planejamento-ação-reflexão, formando um movimento espiralar crescente que se torna mais largo, em termos de conhecimento, em cada volta percorrida. Pode servir de base para o desenvolvimento de pesquisas que foquem a formação do professor ou a aprendizagem dos estudantes. É preciso definir previamente os conhecimentos curriculares e didáticos que devem movimentar as espirais a traçar. Um fator a atender é que, para que ocorra o desenvolvimento do processo formativo, a quantidade de espirais a serem utilizadas depende das circunstâncias desse processo. Existem três termos basilares da espiral: ação, planejamento e reflexão.

Conforme indica a Figura 1, a ação será ação diagnóstica inicial e ação em sala de aula. A reflexão pode ser teórica ou empírica e o planejamento pode ser realizado em pequeno ou em grande grupo. A ação é circunscrita ao que se refere às atividades a serem realizadas com os estudantes. Para efeito de pesquisa e para iniciar o processo formativo apoiando-se na realidade da sala de aula e da escola, a ação diagnóstica visa levantar dados referentes à aprendizagem dos estudantes a respeito do conteúdo a ser trabalhado durante o processo formativo, fornecendo elementos que subsidiem as discussões a respeito da aprendizagem dos estudantes. Se a parceria e as bases colaborativas já estiverem firmadas para o desenvolvimento da formação, o próprio professor poderá aplicar o instrumento diagnóstico, contando com o assessoramento dos pesquisadores. A ação em sala de aula é desenvolvida pelo professor em sua própria sala de aula. Essa ação é planejada durante o encontro formativo, tomando como base resultados da ação diagnóstica inicial e a discussão feita no momento que antecede ao planejamento a respeito do conhecimento didático (em suas quatro vertentes). A ação diagnóstica final, como etapa de pesquisa, visa analisar os efeitos do processo formativo na aprendizagem do estudante.

$\mathrm{Na}$ espiral RePARe, as reflexões estão relacionadas aos momentos de pensar e repensar o que é desenvolvido com o professor quando se efetiva cada espiral. A reflexão teórica é feita sobre os resultados da ação diagnóstica inicial (desempenho e esquemas cognitivos dos estudantes) e sobre o conhecimento didático. Como consequência da reflexão teórica, tem-se a elaboração do planejamento que será desenvolvido em sala de aula (ação em sala de aula). A reflexão empírica é fomentada em um grupo pequeno, formado por professores que atuem num mesmo ano ou ciclo escolar. Na sequência, deve ser fomentada 
num grande grupo, com todos os participantes do grupo colaborativo ${ }^{1}$. A reflexão empírica é feita sobre os resultados da ação em sala de aula, considerando a forma como foi desenvolvida pelo professor e a aprendizagem dos estudantes (desempenhos, esquemas, compreensões sobre o conteúdo matemático, dificuldades), oportunizando reflexões sobre o conhecimento didático (conhecimento do aluno e de seus processos de aprendizagem, o conhecimento dos processos de trabalho na sala de aula, conhecimento do currículo e o conhecimento da Matemática). Os apontamentos feitos pelo grande grupo na reflexão empírica são, consequentemente, levados em conta no novo planejamento a ser efetuado.

O planejamento ocorre num movimento similar ao da reflexão e decorre dos resultados das reflexões (empírica e teórica). É nesse momento que são elaboradas as tarefas a serem desenvolvidas na ação da sala de aula. Os professores, reunidos, planejam em pequenos grupos as tarefas sobre o conteúdo matemático focado na reflexão teórica e considerando os resultados da reflexão empírica realizada sobre os resultados do desenvolvimento em sala de aula do planejamento anterior. Na sequência, ocorre o planejamento no grande grupo e as tarefas planejadas são discutidas coletivamente com todos os participantes do grupo colaborativo.

\section{0 processo formativo desenvolvido}

O processo formativo foi desenvolvido no âmbito do Programa Observatório da Educação, com o projeto de pesquisa intitulado "Um estudo sobre o domínio das Estruturas Multiplicativas no Ensino Fundamental (E-mult)"2. O Grupo de Pesquisa em Educação Matemática, Estatística e em Ciências (GPEMEC) desenvolveu o processo formativo em três escolas. Nesse estudo, referimo-nos apenas à Escola $\mathrm{C}^{3}$. A escolha dessa escola justifica-se por ser a primeira vez que, nela, o GPEMEC desenvolveu a formação. Os professores participaram voluntariamente. No intuito de iniciar a constituição do grupo colaborativo ${ }^{4}$, a equipe de pesquisadores iniciou, em 2013, o contato com a Escola C e realizou duas reuniões para apresentar e discutir o projeto com a direção e a coordenação pedagógica. Em 2014, foram realizadas mais duas reuniões com a direção, a coordenação e com os professores. $\mathrm{O}$

\footnotetext{
${ }^{1}$ Grupo colaborativo é compreendido como um grupo formado por todos os participantes do processo formativo (professores, coordenadores pedagógicos, pesquisadores, estudantes de graduação e de pós-graduação) para a realização de um trabalho colaborativo.

2 Projeto número 15727, financiado pela Coordenação de Aperfeiçoamento de Pessoal do Nível Superior (CAPES).

${ }^{3}$ Preservando a identidade, adotamos nomes fictícios para a escola e a professora.

${ }^{4}$ Em sua constituição, foi considerado grupo colaborativo.
} 
grupo colaborativo foi constituído, inicialmente, por 13 professores que atuavam do $1^{\circ}$ ao $5^{\circ}$ ano da escola. Participaram, também, uma coordenadora pedagógica, uma professora de tutoria (que atendia os estudantes com dificuldades em turno oposto), um mestrando em Educação Matemática e duas pesquisadoras.

A fim de traçar o perfil dos participantes, em setembro de 2014, os professores responderam a um questionário de perfil do professor e decidiram que, para 2015, o dia de sexta-feira, em duas horas de Atividade Complementar (planejamento semanal), era o melhor momento para realizar os encontros formativos presenciais. Os encontros virtuais seriam realizados uma ou duas vezes por mês em sessões de duas horas e se destinariam à discussão do conhecimento da Matemática e do currículo.

Para a ação diagnóstica inicial, a equipe de pesquisadores discutiu com os professores os procedimentos para aplicar o instrumento diagnóstico com os estudantes. Uma semana depois, os professores aplicaram os instrumentos simultaneamente a todos os estudantes, e os pesquisadores acompanharam a aplicação.

No sexto encontro presencial, o grupo colaborativo avaliou que duas horas eram insuficientes para os encontros e passaram a se reunir aos sábados por quatro horas. O Quadro 1 retrata o movimento espiralar que compôs o processo formativo presencial na Escola C, de julho de 2015 a janeiro de 2016. Esse quadro apresenta as nuances do processo formativo presencial que decorreu em dez encontros (28 horas), com o movimento em seis espirais formativas.

\begin{tabular}{|c|c|c|c|}
\hline $\begin{array}{c}\text { Movimento } \\
\text { espiralar }\end{array}$ & Procedimentos realizados e conceitos abordados & $\begin{array}{l}\text { Encontro/ } \\
\text { horas }\end{array}$ & Espiral \\
\hline $\begin{array}{l}\text { Ação } \\
\text { diagnóstica } \\
\text { inicial } 1\end{array}$ & Aplicação do instrumento diagnóstico com os estudantes & $\begin{array}{l}\text { Pré-processo } \\
\text { formativo }\end{array}$ & $\begin{array}{l}\text { Subsidiar } \\
\text { as } \\
\text { espirais }\end{array}$ \\
\hline $\begin{array}{l}\text { Reflexão } \\
\text { teórica } 1 \text { - } \\
\text { diagnóstico }\end{array}$ & $\begin{array}{l}\text { Sobre o desempenho e os esquemas dos estudantes em situações (tarefas) } \\
\text { de proporção simples classe um para muitos. Discussão dos elementos } \\
\text { conceituais. }\end{array}$ & \multirow{2}{*}{$\begin{array}{l}1^{\circ} \text { em duas } \\
\text { horas }\end{array}$} & \multirow{4}{*}{1} \\
\hline $\begin{array}{c}\text { Planejamento } \\
1 \\
\end{array}$ & $\begin{array}{l}\text { Grupo pequeno elabora situações (tarefas) de proporção simples classe um } \\
\text { para muitos, planeja a condução da aula e discute em grupo grande. }\end{array}$ & & \\
\hline $\begin{array}{l}\text { Ação } 1 \text { em } \\
\text { sala de aula }\end{array}$ & Desenvolvimento da aula do planejamento 1. & $\begin{array}{l}\text { Entre o } 1^{\circ} \text { e o } \\
2 .^{\circ} \text { encontro }\end{array}$ & \\
\hline $\begin{array}{l}\text { Reflexão } \\
\text { empírica } 1- \\
\text { resultados da } \\
\text { ação } 1\end{array}$ & $\begin{array}{l}\text { Evidenciando desenvolvimento da ação } 1 \text {, a aprendizagem dos estudantes } \\
\text { (desempenhos, esquemas, compreensões, dificuldades). Ajustes para o } \\
\text { próximo planejamento: campo numérico e interpretação das situações } \\
\text { pelos estudantes. }\end{array}$ & $\begin{array}{l}2^{\circ} \text { em duas } \\
\text { horas }\end{array}$ & \\
\hline $\begin{array}{l}\text { Reflexão } \\
\text { teórica } 2 \text { - } \\
\text { diagnóstico } \\
\end{array}$ & $\begin{array}{l}\text { Sobre o desempenho e os esquemas dos estudantes em situações (tarefas) } \\
\text { de comparação multiplicativa. Discussão dos elementos conceituais. }\end{array}$ & \multirow{2}{*}{$\begin{array}{c}3^{\circ} \text { em duas } \\
\text { horas }\end{array}$} & \multirow{4}{*}{2} \\
\hline $\begin{array}{c}\text { Planejamento } \\
2 \\
\end{array}$ & $\begin{array}{l}\text { Grupo pequeno elabora situações (tarefas) de comparação multiplicativa, } \\
\text { planeja a condução da aula e discute em grupo grande. }\end{array}$ & & \\
\hline $\begin{array}{c}\text { Ação } 2 \text { em } \\
\text { sala de aula }\end{array}$ & Desenvolvimento da aula do planejamento 2 (comparação multiplicativa). & $\begin{array}{l}\text { Entre o } 3^{\circ} \text { e o } 4^{\circ} \\
\text { encontro }\end{array}$ & \\
\hline $\begin{array}{l}\text { Reflexão } \\
\text { empírica } 2- \\
\text { ação } 2 \\
\end{array}$ & $\begin{array}{l}\text { Resultados da ação } 2 \text { (desempenhos, esquemas, compreensões, } \\
\text { dificuldades). Ajustes para o próximo planejamento: interpretação das } \\
\text { situações pelos estudantes. }\end{array}$ & $\begin{array}{l}4^{\circ} \text { em duas } \\
\text { horas }\end{array}$ & \\
\hline
\end{tabular}




\begin{tabular}{|c|c|c|c|}
\hline $\begin{array}{l}\text { Reflexão } \\
\text { teórica } 3\end{array}$ & $\begin{array}{l}\text { Reflexão sobre o desempenho e os esquemas dos estudantes em três } \\
\text { situações do instrumento diagnóstico de proporção simples muito para } \\
\text { muitos. Discussão dos elementos conceituais e relação dessa classe de } \\
\text { situações. }\end{array}$ & \multirow[t]{2}{*}{$\begin{array}{l}5^{\circ} \text { em duas } \\
\text { horas }\end{array}$} & \multirow{4}{*}{3} \\
\hline $\begin{array}{l}\text { Planejamento } \\
3\end{array}$ & $\begin{array}{l}\text { Grupo pequeno elabora duas situações (tarefas) de proporção simples } \\
\text { muitos para muitos. Planeja a condução da aula. }\end{array}$ & & \\
\hline $\begin{array}{l}\text { Ação } 3 \text { em } \\
\text { sala de aula }\end{array}$ & $\begin{array}{l}\text { Desenvolvimento da aula do planejamento } 3 \text { (proporção simples classe } \\
\text { muitos para muitos). }\end{array}$ & $\begin{array}{l}\text { Entre o } 5^{\circ} \text { e o } 6^{\circ} \\
\text { encontro }\end{array}$ & \\
\hline $\begin{array}{l}\text { Reflexão } \\
\text { empírica } 3- \\
\text { ação } 3 \\
\end{array}$ & $\begin{array}{l}\text { Resultados da ação } 3 \text { (desempenhos, esquemas, compreensões, } \\
\text { dificuldades). Ajustes para o próximo planejamento: interpretação das } \\
\text { situações e operacionalização da multiplicação e divisão. }\end{array}$ & $\begin{array}{l}6^{\circ} \text { em duas } \\
\text { horas }\end{array}$ & \\
\hline $\begin{array}{l}\text { Reflexão } \\
\text { teórica } 4\end{array}$ & $\begin{array}{l}\text { Reflexão sobre o desempenho e esquemas dos estudantes em situações } \\
\text { (tarefas) de configuração retangular do diagnóstico. Discussão sobre os } \\
\text { elementos conceituais e relação dessa classe de situações. }\end{array}$ & \multirow{2}{*}{$\begin{array}{l}7^{\circ} \text { em quatro } \\
\text { horas }\end{array}$} & \multirow{4}{*}{4} \\
\hline $\begin{array}{l}\text { Planejamento } \\
4\end{array}$ & $\begin{array}{l}\text { Grupo pequeno elabora duas situações (tarefas) de configuração } \\
\text { retangular. Planeja a condução da aula. }\end{array}$ & & \\
\hline $\begin{array}{l}\text { Ação } 4 \text { em } \\
\text { sala de aula }\end{array}$ & Desenvolvimento da aula do planejamento 4 (configuração retangular). & $\begin{array}{l}\text { Entre o } 7^{\circ} \text { e o } 8^{\circ} \\
\text { encontro }\end{array}$ & \\
\hline $\begin{array}{l}\text { Reflexão } \\
\text { empírica } 4- \\
\text { ação } 4\end{array}$ & $\begin{array}{l}\text { Resultados da ação } 4 \text { (desempenhos, esquemas, compreensões, } \\
\text { dificuldades). Ajustes para o próximo planejamento: medidas de } \\
\text { comprimento, conceitos de comprimento, largura e área. }\end{array}$ & \multirow{3}{*}{$\begin{array}{l}8^{\circ} \text { em duas } \\
\text { horas }\end{array}$} & \\
\hline $\begin{array}{l}\text { Reflexão } \\
\text { teórica } 5\end{array}$ & $\begin{array}{l}\text { Reflexão sobre o desempenho e esquemas dos estudantes em situações } \\
\text { (tarefas) de configuração retangular do instrumento diagnóstico. } \\
\text { Discussão sobre os elementos conceituais. }\end{array}$ & & \multirow{4}{*}{5} \\
\hline $\begin{array}{l}\text { Planejamento } \\
5\end{array}$ & $\begin{array}{l}\text { Grupo pequeno elabora duas situações (tarefas) de configuração } \\
\text { retangular. Planeja a condução da aula. }\end{array}$ & & \\
\hline $\begin{array}{l}\text { Ação } 5 \text { em } \\
\text { sala de aula }\end{array}$ & Desenvolvimento da aula do planejamento 5 (configuração retangular). & $\begin{array}{l}\text { Entre o } 8^{\circ} \text { e o } 9^{\circ} \\
\text { encontro }\end{array}$ & \\
\hline $\begin{array}{l}\text { Reflexão } \\
\text { empírica } 5 \text { - } \\
\text { ação } 5\end{array}$ & $\begin{array}{l}\text { Resultados da ação } 5 \text { (desempenhos, esquemas, compreensões, } \\
\text { dificuldades). Ajustes para o próximo planejamento: interpretação das } \\
\text { situações e a operacionalização da multiplicação e da divisão. }\end{array}$ & \multirow{3}{*}{$\begin{array}{l}9^{\circ} \text { em quatro } \\
\text { horas }\end{array}$} & \\
\hline $\begin{array}{l}\text { Reflexão } \\
\text { teórica } 6\end{array}$ & $\begin{array}{l}\text { Reflexão sobre o desempenho e esquemas dos estudantes em duas } \\
\text { situações (tarefas) de combinatória do instrumento diagnóstico. Discussão } \\
\text { sobre os elementos conceituais. }\end{array}$ & & \multirow{4}{*}{6} \\
\hline $\begin{array}{l}\text { Planejamento } \\
6\end{array}$ & $\begin{array}{l}\text { Grupo pequeno elabora duas situações (tarefas) de combinatória. Planeja a } \\
\text { condução da aula. }\end{array}$ & & \\
\hline $\begin{array}{l}\text { Ação } 6 \text { em } \\
\text { sala de aula }\end{array}$ & Desenvolvimento da aula do planejamento 6 (combinatória). & $\begin{array}{l}\text { Entre o } 9^{\circ} \text { e o } \\
10^{\circ} \text { encontro }\end{array}$ & \\
\hline $\begin{array}{l}\text { Reflexão } \\
\text { empírica } 6- \\
\text { ação } 6\end{array}$ & $\begin{array}{l}\text { Discussão sobre os resultados da ação } 6 \text {. O professor prevê retomar com } \\
\text { os estudantes no próximo ano letivo. Ao final do encontro foi respondido } \\
\text { o instrumento de avaliação final do processo formativo }\end{array}$ & $\begin{array}{c}10^{\circ} \text { em quatro } \\
\text { horas }\end{array}$ & \\
\hline
\end{tabular}

Quadro 1 - Procedimentos realizados e conceitos abordados nos encontros formativos presenciais Fonte: Dados da pesquisa.

As aulas foram planejadas com a seguinte dinâmica: o professor apresenta as situações (tarefas) para que o estudante responda, sem nenhuma explicação prévia, observa as respostas dadas, os esquemas utilizados e as suas dificuldades. Em seguida, faz uma intervenção que pode assumir formas distintas: leitura interpretativa das situações, socialização das respostas dos estudantes, uso de material manipulável para auxiliar na contagem ou para representar as situações (principalmente do $1^{\circ}$ ao $3^{\circ}$ ano), uso de diagramas de Vergnaud (principalmente no $5^{\circ}$ ano) e, por fim, a sistematização da resolução. No momento da intervenção, o professor continua a identificar as dificuldades dos estudantes, objetivando planejar outras formas de intervenção e fazer a revisão de elementos conceituais. 
Foram realizados oito encontros virtuais (16 horas) com uso da plataforma Moodle, nos quais os professores leram previamente os textos de Magina, Santos e Merlini (2014) e Santos (2015) que subsidiaram as discussões.

\section{Metodologia}

Esta é uma pesquisa de abordagem qualitativa, complementado pelas premissas do método interpretativo que requer "habilidades de observação, comparação, contraste e reflexões que todo humano possui”" (ERICKSON, 1986, p. 157), fazendo uso da interpretação que privilegie a observação e a reflexão de maneira sistemática e discutida.

Para este estudo, nos referimos ao processo formativo presencial da Escola C. A constituição do grupo colaborativo foi delineada conforme a Tabela 1.

Tabela 1 - Integrantes do grupo colaborativo

\begin{tabular}{c|c|c|c|c|c|c}
\hline Escola & $\begin{array}{l}\text { Professores do } \\
\mathbf{1 .}^{\circ} \text { ao 5. }{ }^{\circ} \text { ano }\end{array}$ & Pesquisadores & $\begin{array}{l}\text { Estudantes } \\
\text { de graduaçãa }\end{array}$ & $\begin{array}{l}\text { Estudantes de } \\
\text { pós-graduação }\end{array}$ & $\begin{array}{l}\text { Professor } \\
\text { de tutoria }\end{array}$ & $\begin{array}{l}\text { Coordenador } \\
\text { pedagógico }\end{array}$ \\
\hline $\mathrm{C}$ & 13 & 2 & - & 1 & 1 & 1 \\
\hline \multicolumn{6}{c}{ Fonte: Dados da pesquisa }
\end{tabular}

No universo dos 13 professores que concluíram o processo formativo na Escola C, selecionamos uma professora para este estudo. A professora Mara foi escolhida por ter $100 \%$ de participação nos encontros presenciais e virtuais, ter desenvolvido todas as ações programadas para a sala de aula e ter respondido a todos os instrumentos de pesquisa. A professora era formada em Pedagogia, há nove anos, e atuava na rede pública de ensino há mais de seis anos. No ano 2015, lecionava como professora polivalente, em duas turmas do $3^{\circ}$ ano. Oficialmente, para aquele ano escolar, foram atribuídas três horas-aula por semana à Matemática.

Foram utilizados três instrumentos de coleta de dados. O primeiro foi um questionário do perfil do professor, cujo objetivo principal era compreender os traços do conhecimento profissional, no que diz respeito às perspectivas anteriores ao processo formativo e às experiências pessoais em relação ao conhecimento didático nas vertentes do conhecimento da Matemática e do currículo. O segundo instrumento foi um questionário de avaliação final do processo formativo com o objetivo de identificar as perspectivas posteriores, imediatamente depois do processo formativo, relativas às experiências individuais e coletivas vivenciadas e aos conhecimentos didáticos mobilizados nesse processo. O terceiro foi uma entrevista semiestruturada que objetivava compreender os conhecimentos didáticos mobilizados pela 
professora, durante o processo formativo, que perduravam em suas perspectivas depois do processo.

Para analisar as respostas dadas nos três instrumentos de coleta de dados, foram utilizados dois blocos de análise e categorias que se reportam ao quadro teórico apresentado anteriormente (Quadro 2).

\begin{tabular}{|l|l|}
\hline Bloco de análise & Categorias \\
\hline Perspectivas & $\begin{array}{l}\text { - Baseadas em ações anteriores ao processo formativo } \\
\text { - Baseadas em ações posteriores ao processo formativo }\end{array}$ \\
\hline Conhecimento didático & $\begin{array}{l}\text { - Conhecimento da matemática } \\
\text { - Conhecimento dos processos de trabalho na sala de aula. }\end{array}$ \\
\hline
\end{tabular}

Quadro 2- Blocos e categorias de análise Fonte: Dados da pesquisa.

As respostas dadas foram analisadas dentro dos dois blocos de análise, interpretando e descrevendo as respostas da professora. Ressaltamos que as tarefas respondidas pelos estudantes durante as seis ações de sala de aula, bem como os materiais usados (jogos, slides, material concreto, cartazes) e fotografias eram apresentados pela professora nos momentos de reflexão no pequeno e no grande grupo. Esse retorno trazia evidências da realização da prática da professora.

\section{Resultados}

\subsection{Perspectivas e conhecimento didático antes do processo formativo}

Iniciamos por procurar compreender as perspectivas da professora a respeito do seu gosto pela Matemática, desde a sua trajetória estudantil. Mara afirmou que detestava Matemática, expressando uma imagem negativa da disciplina. Questionada se, com o passar dos anos, esse gosto mudou, escreveu que sim e justificou.

Mudou, porque sinto necessidade de melhorar, para que os meus alunos não tenham as mesmas experiências ruims que eu tive (Mara, 2014, questionário do perfil).

Com base em suas experiências frustrantes com a disciplina, Mara afirmou que, durante a sua trajetória estudantil, teve uma perspectiva negativa em relação à Matemática. Sinaliza uma intuição prospectiva expressa por uma disposição interior motivada para uma movimentação de comportamento, a partir de suas convicções e de seus aprendizados do passado real, referindo a intenção de não promover experiências negativas aos seus alunos. Demonstra, em suas afirmações, uma responsabilidade na realização do seu fazer docente. 
Visando compreender a relação que a professora tinha com o conhecimento da Matemática e do seu ensino, foi solicitado que enumerasse, de um (mais seguro) a quatro (menos seguro), a sua segurança no ensino de diferentes blocos de conteúdos (Tratamento da Informação; Espaço e Forma; Números e Operações; Grandezas e Medidas). Mara indicou dois blocos - Tratamento da Informação, Grandezas e Medidas - como aqueles em que se sentia mais segura para ensinar. Indicou outros dois, Números e Operações, Espaço e Forma, como aqueles em que se sentia menos segura para ensinar. Elencou dois motivos para justificar as suas indicações.

Tenho dificuldades com cálculos e pouco conhecimento quanto às formas geométricas (Mara, 2014, questionário do perfil).

No domínio do conhecimento matemático, a professora destacou as suas dificuldades com cálculos e relacionou os cálculos ao bloco Números e Operações. Nesse caso, para além de possíveis dificuldades com os procedimentos matemáticos, destaca, sobretudo, que reflete em dificuldades no modo de os ensinar. Ademais, afirmou ter pouco conhecimento das formas geométricas, mas não indicou se essas dificuldades se estendiam às definições geométricas, propriedades, relações ou cálculo de áreas e volumes ou ao seu ensino.

A professora afirmou que poderia ensinar Matemática em qualquer turma do $1^{\circ}$ ao $9^{\circ}$ ano e elencou o seguinte motivo para essa sua preferência.

Como tenho dificuldades, qualquer ano requer de mim dedicação e estudo (Mara, 2014, questionário do perfil).

Essas perspectivas indicam que suas próprias dificuldades com o conhecimento matemático eram motivadoras para ensinar em qualquer ano escolar. Parece-nos, sobretudo, um cenário desolador, pois a professora exterioriza falta de confiança em seus conhecimentos matemáticos e didáticos para lecionar em qualquer ano escolar, expressando uma ideia de necessidade de planejamento e dedicação ao estudo de conteúdos matemáticos e do modo de ensina-los.

\subsection{Perspectivas e conhecimentos didáticos no fim do processo formativo}

O processo formativo visava intervir na prática do professor no sentido de planejar tarefas a serem desenvolvidas em sala de aula, formas de conduzir a aula e intervir com o estudante, discutir a respeito do conteúdo matemático e a gestão do conteúdo das estruturas multiplicativas ao longo do Ensino Fundamental, além de promover reflexões a respeito dos resultados do desenvolvimento das tarefas em sala de aula e dos esquemas de solução 
utilizados pelos estudantes. Quando questionada sobre como avaliava esses parâmetros desenvolvidos no processo formativo, Mara disse ter sido satisfatório e justificou.

Essa foi a primeira formação que me proporcionou estudar a teoria, aplicar em sala de aula e refletir sobre os resultados e estratégias [de resolução dos estudantes] (Mara, 2016, questionário final).

A justificação de Mara evidencia as suas perspectivas evocadas comparativamente com outros processos formativos em que participou e se refere aos elementos pertinentes da prática formativa da Espiral RePARe. Quando cita que "proporcionou estudar a teoria" mostra que as reflexões teóricas e as seções virtuais oportunizaram-lhe momentos de estudo. Os momentos de reflexão empírica focavam a reflexão sobre os resultados dos estudantes a partir das ações planejadas na formação e desenvolvidas em sala de aula e na avaliação. Mara indica apoiar-se nesses fatores para justificar sua satisfação com o processo formativo. O alcance das ações formativas para a sala de aula fica expresso nas suas colocações e demonstra uma postura positiva em relação ao movimento exercido no processo formativo e em relação aos conhecimentos sobre processos de trabalho em sala de aula e de aprendizagem do estudante.

A temática de cada encontro formativo baseava-se nos eixos e nas classes das situações multiplicativas. Questionada se essa organização facilitou o entendimento em relação ao conhecimento matemático, a professora respondeu positivamente.

Sim, ampliou o meu conhecimento das diversas situações [do Campo Multiplicativo] e essas situações proporcionam o desenvolvimento do raciocínio dos alunos (Mara, 2015, questionário final).

Mara afirmou que o seu conhecimento matemático em relação às situações do Campo Multiplicativo foi ampliado e que essa ampliação permite o desenvolvimento do raciocínio e, consequentemente, a aprendizagem dos estudantes. Demonstra, com isso, um movimento reflexivo que parte do conhecimento que adquiriu para os resultados observados nos processos de trabalho na sala de aula.

A professora avaliou como muito satisfatório o processo formativo com vista à melhoria de sua prática pedagógica para o ensino de Matemática e justificou.

É muito importante ter domínio do conhecimento e do que vamos tratar em sala de aula. Nos dá segurança principalmente do que queremos alcançar (Mara, 2015, questionário final).

O nível de satisfação dela foi justificado pelo domínio do conhecimento e pela segurança com o que vai realizar em sala de aula. É possível inferir que Mara faz uma ligação entre diferentes vertentes do conhecimento didático, pois o que vai "tratar em sala de aula", 
perpassa pelas quatro vertentes desse conhecimento, trazendo evidências de que suas perspectivas sobre o processo formativo buscam assegurar, na memória, um estado de "segurança" para o trabalho em sala de aula. Nessa resposta, observa-se uma conduta e um comportamento muito diferentes do que foi colocado por Mara antes do processo formativo, pois está pautada em domínio e segurança, e não mais em dificuldades, experiências negativas ou reduzido conhecimento. Os resultados indicam a possibilidade de diálogo entre ter confiança no domínio de conceitos matemáticos (elementos do conhecimento didático) e a prática de sala de aula, proporcionando novas perspectivas profissionais para a professora no que diz respeito ao que pretende alcançar para o ensino de Matemática.

\subsection{Perspectivas e conhecimentos didáticos dois anos depois do processo formativo}

Visando compreender as influências do processo formativo para o conhecimento didático e para a prática de Mara, perdurados por dois anos depois do fim do processo formativo, foi realizada uma entrevista semiestruturada com a professora.

Ao questionar a respeito das perspectivas em relação às vertentes do conhecimento dos processos de trabalho na sala de aula, Mara afirma que foram muitas as informações.

Se eu pudesse, não esqueceria nenhuma das informações, gosto de rever os textos, gosto de falar, de compartilhar com as pessoas essa coisa toda que aprendi; foi um ano estudando os textos, participando dos chats [plataforma Moodle], reuniões, foi um aprendizado muito rico. E, com relação à matemática, antes eram grandes os questionamentos, as angústias; $e$ a formação deu uma aquietada e, por outro lado, despertou um desejo de melhorar nos outros eixos matemáticos (Mara, 2017, entrevista).

As colocações de Mara baseiam-se em novas imagens e em um novo comportamento ditado por uma disposição interior, assume um comportamento afetado por novos propósitos do conhecimento dos processos de trabalho na sala de aula, o conhecimento matemático e a sua interpretação da Matemática a ser trabalhada em sala de aula. Ela assume, assim, uma nova perspectiva a respeito do ensino dessa disciplina.

As perspectivas anteriores ao processo formativo faziam com que Mara se expressasse negativamente em relação ao conhecimento matemático. As perspectivas posteriores ao processo formativo vão numa direção diferente.

Matemática para mim, não é que não significava nada, significava que eu não sabia. Como trabalhar eu sabia o que aprendi na escola, mas, diante das dificuldades dos meus alunos e da necessidade, eu não tinha como fazer nada. A formação mudou a minha prática, tornou mais leve o meu trabalho. Hoje, consigo planejar uma aula de matemática que me satisfaz. Na aula, penso: "eu podia ter pensado isso, eu podia fazer assim que iria ficar melhor. Mas, posso fazer para a próxima vez". Eu consigo ter algo que me satisfaz; porque planejava, mas não me satisfazia; ficava com aquela coisa "não está bom" (Mara, 2017, entrevista). 
Mara enfatiza que os conhecimentos dos processos de trabalho na sala de aula, mobilizados durante o processo formativo, colaboraram para o seu fazer em sala de aula, a exemplo de como lidar com o planejamento das aulas de Matemática e formas de conduzir a aula, colocando-o em prática, elencando reflexões e ações para outros planejamentos e outras aulas a realizar. As perspectivas evocadas do que foi vivenciado antes do processo formativo servem de base para comparação com as perspectivas posteriores e elas trazem perspectivas para a ação do presente, ao afirmar que "hoje eu consigo planejar uma aula de matemática que me satisfaz".

Visando compreender as perspectivas de Mara diante do conhecimento matemático específico tratado no processo formativo, questionamos se a prática docente posterior ao processo formativo teve alterações quanto ao ensino das estruturas multiplicativas. A professora indica que, embora oficialmente estejam atribuídas três horas-aula para a Matemática, anteriormente não chegava a lecionar esse conteúdo.

No $3^{\circ}$ ano, eu nem chegava a trabalhar multiplicação. Da grade de horário, a matemática era lá no final, apenas num momento. Era a minha prática. Porque, quando não se sabe como fazer, fica difícil. Então, quando a gente trabalha no ciclo de alfabetização, a ênfase do município, era língua portuguesa e o que sobrava era para as outras disciplinas; então não trabalhava [matemática] (Mara, 2017, entrevista).

Atualmente, no sistema educacional brasileiro, o $3^{\circ}$ ano do Ensino Fundamental é o último ano do ciclo de alfabetização. Em suas reflexões, Mara explica que as perspectivas anteriores ao processo formativo sobre a sua prática referente ao conteúdo matemático, ancorava-se em dois pontos: não ter o conhecimento da Matemática e a ênfase dada pela organização municipal de Educação para o ensino da Língua Portuguesa no ciclo de alfabetização, mesmo com as atribuições oficiais da carga horária. Contudo, as perspectivas posteriores ao processo formativo parecem refletir as discussões e reflexões feitas.

Depois da formação, é um discurso meu em todos os planejamentos: "vamos mudar esse horário, gente, vamos colocar matemática!". As pessoas olham para mim, vê assim: "ah, a professora que ama matemática". Porque eu fico tentando, pois descobri a importância. Matemática caminha junto com língua portuguesa. Tem coisas em língua portuguesa que precisam do conhecimento e do conceito matemático, se não, o menino não avança. Então, mudou e muito (Mara, 2017, entrevista).

A professora apresenta outra postura em suas perspectivas posteriores ao processo formativo, elencando fatos de suas tentativas de mudança para alterar a rotina posta no próprio sistema de Educação do munícipio. Além disso, as suas novas perspectivas dão mais importância ao ensino da Matemática e sua ligação com o ensino da Língua Portuguesa. 
Mara não especifica um conteúdo matemático, mas generaliza para o conhecimento matemático como um todo. Ressaltamos que, antes do processo formativo, a professora expressou clareza sobre a importância de não transferir as suas perspectivas negativas, em relação à Matemática, para o estudante. Exteriorizava ser uma professora desmotivada para o ensino da disciplina e com dificuldades com cálculo. Dois anos depois do processo formativo, as imagens que ela relata são outras. Afirma lidar com o conhecimento dos processos de trabalho na sala de aula com mais confiança, consegue ver a importância da disciplina dentro do currículo do ciclo de alfabetização (do $1^{\circ}$ ao $3^{\circ}$ ano) e revela atitudes e conhecimentos que vão para além das fronteiras de olhares simplistas dos conteúdos matemáticos, observando a importância do seu ensino para o crescimento cognitivo do estudante na área de Língua Portuguesa.

Ainda em relação à sua prática em sala de aula, a professora ressalta que mudou depois do processo formativo.

Mudou no sentido de valorizar mais o que aluno diz e pensa. Isso, também, foi um ponto bem forte. Depois da formação, eu me sinto assim com mais curiosidade, com mais tranquilidade de esperar o que o aluno vai dar de resposta, o que ele vai trazer para mim, isso foi além. Porque vai para todas as disciplinas (Mara, 2017, entrevista).

Mara ressalta os processos de trabalho em sala de aula e os processos de aprendizagem dos alunos. Afirma ter novas perspectivas, passando a valorizar o pensamento e a participação deles em suas aulas, não apenas para a Matemática, mas para todas as disciplinas. Desse modo, traz elementos que nos remetem a reflexões empíricas tensionadas pela espiral formativa.

A prática envolve a condição de estabelecer regras e normas de atuação do professor e do estudante no sentido de promover a aprendizagem. Para a sua prática de ensino dos conteúdos das estruturas multiplicativas, Mara apontou contribuições.

Quebrou vários mitos. Um foi quando aprendi durante a formação, que criança de seis anos tem condição de aprender a multiplicar, achei isso fantástico! Passei a querer compreender mais, ampliar o meu conhecimento para eu poder proporcionar isso aos meus alunos. E a questão, também, de deixar o "arme e efetue" em segundo plano (Mara, 2017, entrevista).

Mara quebrou mitos e passou a perceber o ensino da multiplicação com outros pensamentos. Saber que pode abordar esse conceito desde o $1^{\circ}$ ano e trabalhar essas ideias sem o algoritmo configura perspectivas posteriores ao processo formativo, motivadas pelas reflexões teóricas e empíricas sobre o conhecimento matemático proporcionadas nas espirais formativas. A professora valorizou sua mudança de pensamentos.

Eu já me incomodava com o "arme e efetue" aquela coisa solta, que não tinha uma origem, que não veio de lugar nenhum. Então, quando na formação, eu comecei a ver essa 
multiplicação contextualizada. Como é prático, como é do cotidiano; isso, também, mudou e traz assim um novo ânimo, uma vontade de trabalhar daquela forma, ver o aluno assim apto, capaz, se sentindo desafiado e corajoso, mais seguro dele (Mara, 2017, entrevista).

Dois anos depois do processo formativo, Mara evidencia a mobilização de seus conhecimentos, do que ensinar e como ensinar em relação às operações de multiplicação e de divisão. Elenca dois mitos que podem ser aterrorizantes para professores dos Anos Iniciais, que é o fato de não poder trabalhar as ideias das operações desde o princípio da escolaridade e de trabalhar o "arme e efetue" sem sentido. As suas declarações trazem evidências da mobilização de conhecimento que perdura para o seu fazer em sala de aula, que está interligado com a gestão do que ensinar e como ensinar, ao movimento de ação com o estudante, transferindo a sua própria motivação para a motivação do estudante.

De uma maneira geral, os conhecimentos didáticos mobilizados durante o processo formativo parecem motivar perspectivas posteriores ao processo formativo que elencam uma postura mais positiva da professora.

Foi uma professora que entrou e foi outra que acabou a formação. Me fez até ficar assim, mais contente com meu trabalho. Porque, quem está em sala de aula tem muitas insatisfações com o seu fazer, com a sua prática; e, às vezes, a gente é solitário, sozinho, você não tem com quem partilhar aquilo (Mara, 2017, entrevista).

Mara expressa suas perspectivas em relação ao fato de a prática de ensino ser uma ação isolada e não ter condições e espaços de diálogo sobre esse fazer. O processo formativo oportunizou, nos planejamentos, em grupos pequenos e grandes, momentos de construção e reflexão coletiva, ações inerentes ao trabalho colaborativo. Essas são perspectivas posteriores da professora que indicam a necessidade de se proporcionar esses espaços de diálogo para auxiliar o desenvolvimento da prática de ensino do professor.

As perspectivas expressas por Mara assumem dois patamares que se estabelecem em função da realização do processo formativo, as perspectivas anteriores e as posteriores. Antes de iniciar o processo, a professora evidencia, em suas respostas, perspectivas negativas e desoladoras em relação ao seu conhecimento didático e a sua prática de ensino de Matemática e refere ter pouco conhecimento dos eixos de conteúdo. Depois do processo formativo, essas perspectivas são reveladas de maneira mais positiva com novas posturas e elencando outras formas de conceber a prática de ensino da Matemática, do seu conhecimento sobre as estruturas multiplicativas, conhecimento de processos de aprendizagem do aluno e de processo de trabalho na sala de aula. Esses patamares de conhecimento sugerem que os objetivos postos para o processo formativo foram elencados nas perspectivas da professora. 
Esses resultados revelam que o processo formativo possibilitou um diálogo entre a teoria e a prática da sala de aula da professora, diálogo que perdura por dois anos letivos trazendo indícios de que o modelo de formação favoreceu a mobilização do conhecimento didático da professora.

\section{Considerações finais}

As ações do processo formativo buscavam promover o desenvolvimento profissional e a mobilização do conhecimento profissional do professor de Matemática a partir de reflexões empíricas sobre sua própria atuação em sala de aula. Visavam intervir na prática de ensino, discutir o conteúdo das estruturas multiplicativas e refletir sobre processos de aprendizagem dos estudantes no que diz respeito a esse conteúdo. Essas ações foram notadas pela professora ao indicar que o diálogo entre teoria e prática (JAWORSKI, 2006) proporcionou-lhe novas perspectivas a partir de sua própria prática.

O conhecimento profissional do professor de Matemática relacionado com a prática letiva, ou seja, o conhecimento didático (PONTE; OLIVEIRA, 2002; PONTE, 2012) assume quatro vertentes, que podem ser mobilizadas com foco no desenvolvimento profissional do professor. Antes do processo formativo, a professora exterioriza perspectivas negativas em relação ao conhecimento matemático e ao seu ensino, relata dificuldades com cálculo e geometria, expressa falta de confiança na sua lecionação. O processo formativo enfatizou que o professor precisa conhecer bem o objeto matemático que ensina (BALL; MARK; GEOFFREY, 2008) e ter recursos em que se sinta à vontade para ensina-lo (PONTE, 2012).

Depois do processo formativo, a professora exterioriza perspectivas positivas em relação aos conhecimentos matemático e didático. Ela evidencia um movimento reflexivo que parte do conhecimento didático adquirido, revela resultados positivos na direção do conhecimento dos processos de trabalho na sala de aula, no que se refere à aprendizagem do estudante, afirma ter ampliado o conhecimento matemático, em relação às situações do Campo Multiplicativo e liga essa ampliação ao conhecimento sobre os processos de aprendizagem e de desenvolvimento do raciocínio dos estudantes. Demonstra, com isso, um movimento de reflexão empírica e de aprendizado que parte do conhecimento adquirido em sua prática que foi motivada pelas ligações teóricas oportunizadas no processo. Para Korthagen e Kessels (1999), essa ligação entre teoria e prática mostra-se relevante para a prática em sala de aula. Esse movimento reflexivo da professora foi oportunizado pelas espirais do modelo de prática formativa RePARe, quando se utiliza do processo de reflexão- 
planejamento-ação-reflexão, definido por Magina et al. (2018). As fases das espirais foram apresentadas nas colocações da professora.

Esses resultados podem ser contemplados nas colocações de Mara, passados dois anos da realização do processo formativo, pois a professora continuou evidenciando a mobilização do conhecimento didático, conforme definido por Ponte e Oliveira (2002) e Ponte (2012). Ela referiu ter mais conhecimento da Matemática no que diz respeito à sua interpretação sobre o que deve ser ensinado nas operações de multiplicação e de divisão. Exteriorizou que o conhecimento sobre os processos de aprendizagem do aluno intenciona outras posturas em relação ao processo de ensino em Matemática. Assumiu outra perspectiva sobre o currículo, ao reconhecer a necessidade de valorizar o trabalho em Matemática em vez de deixa-lo para o fim do ano escolar. E, muito especialmente, revelou um conhecimento mais amplo sobre processos de trabalho na sala de aula com perspectivas que afetam positivamente o que ensinar e como ensinar.

\section{Referências}

BALL, D. L.; MARK, H. T.; GEOFFREY, P. Content knowledge for teaching: What makes it special? Journal of Teacher Education, Görükle, Bursa, Turquia, v. 59, p. 389-407, 2008.

ELBAZ, F. Teacher thinking: A study of practical knowledge. London: Croom Helm, 1983.

ERICKSON, F. D. Qualitative methods in research on teaching. In: WITTROCK, M. C. (Ed.). Handbook of research on teaching.

FERREIRA, A. C. Metacognição e desenvolvimento profissional de professores de Matemática: uma experiência de trabalho colaborativo. Tese (Doutorado em Educação: Educação Matemática) Faculdade de Educação, Universidade Estadual de Campinas -Unicamp, Campinas, 2003.

JAWORSKI, B. Research practice into/influencing mathematics teaching and learning development: towards a theoretical framework based on co-learning partnerships. Educational Studies in Mathematics, Switzerland, v. 54, p. 249-282, 2003.

. Theory and practice in mathematics teaching development: Critical inquiry as a model of learning in teaching. Journal of Mathematics Teacher Education, Görükle, Bursa, v. 9, p.187-211, 2006.

JAWORSKI, B.; POTARI, D. Characterising mathematics teaching using the teaching triad. In: OLIVIER, A.; NEWSTEAD, K. (Ed.). Proceedings of the $22^{\text {nd }}$ PME International Conference. Vol. 3. Stellenbosch, South Africa, 1998. p. 88-95.

KORTHAGEN, F. A. J. Linking practice and theory: the pedagogy of realistic teacher education. London: Lawrence Erlbaum, 2001.

KORTHAGEN, F. A. J.; KESSELS. J. P. A. M. Linking theory and practice: Changing the pedagogy of teacher education. Educational Researcher, New York, v. 28, n. 4, p. 4-17, 1999.

LOPES, C. E. O Conhecimento profissional dos professores e suas relações com estatística e 
probabilidade na educação infantil. Tese (Doutorado em Educação: Educação Matemática) Faculdade de Educação, Universidade Estadual de Campinas - Unicamp, Campinas, 2003.

MAGINA, S. M.; P., SANTOS, A. DOS; MERLINI, V. L. O raciocínio de estudantes do ensino fundamental na resolução de situações das estruturas multiplicativas. Ciência e Educação (UNESP. Impresso), Bauru, v. 20, p. 517-533, 2014.

MAGINA, S. M. P.; SANTANA, E. R. dos S.; SANTOS, A. dos; MERLINI, V. L. Espiral RePARe: um modelo metodológico de formação de professor centrado na sala de aula. Revista do Programa de Doutorado da Rede Amazônica de Educação em Ciências e Matemática (REAMEC), Cuiabá, v. 6 , n. 2, p. $01-22$ jul./dez. 2018.

OLIVEIRA, S. A.; PASSOS, C. L. B. O trabalho colaborativo e o desenvolvimento profissional de um grupo de professores dos anos iniciais: olhar para resolução de problemas. Cadernos de Pesquisa, São Luiz do Maranhão, v. 24, n. especial, p. 192 - 207, set./dez. 2017.

PINTO, C. L. L.; LEITE, C. Trabalho colaborativo: um conceito polissêmico. Conjectura: filosofia e educação. Caxias do Sul, v. 19, n. 3, p. 143-170, set./dez. 2014.

PONTE, J. P. Estudiando el conocimiento y el desarrollo profesional del profesorado de matemáticas. In: PLANAS, N. (Ed.). Educación matemática: teoría, crítica y práctica. Barcelona: Graó, 2012. p. 83-98.

PONTE, J. P.; OLIVEIRA, H. Remar contra a maré: a construção do conhecimento e da identidade profissional na formação inicial. Revista de Educação, Lisboa, v. 11, n. 2, p. 145-163, 2002.

PONTE, J. P.; CHAPMAN, O. Mathematics teachers' knowledge and practices. In: GUTIERREZ, A.; BOERO, P. (Ed.). Handbook of research on the psychology of mathematics education: past, present and future. Hamburg: Springer, 2006. p. 461-494.

SANTANA, E. Um estudo sobre o domínio das estruturas multiplicativas no ensino fundamental. Projeto de Pesquisa. Ilhéus: CAPES, 2013.

SANTANA, E.; ALVES, A. A.; NUNES, C. B. A teoria dos campos conceituais num processo de formação continuada de professores. Bolema, Rio Claro, v. 29, n. 53, p. 1162-1180, 2015.

SANTOS, A. dos. Formação de professores e as estruturas multiplicativas: reflexões teóricas e práticas. Curitiba: Appris, 2015.

SCHÖN, D. Educando o profissional reflexivo: um novo design para o ensino e aprendizagem. Tradução Roberto Cataldo Costa. Porto Alegre: Artes Médicas Sul, 2000.

SHULMAN, L. Those who understand: Knowledge growth in teaching. Educational Researcher, New York, 15(2), 1986, p. 3-14.

Knowledge and teaching: Foundations of the new reform. Harvard Educational Review, Cambridge, US, 57(1), 1987, p. 1-22. 